\title{
Penerapan Bahasa Jurnalistik pada Kategori Berita Hukum Kriminal Datariau.com
}

\author{
Ayu Listari' ${ }^{1}$, Ismandianto ${ }^{2}$ \\ Ilmu Komunikasi Fakultas Ilmu Sosial dan Ilmu Politik Universitas Riau ${ }^{1,2}$ \\ Email: listariueo@gmail.com ${ }^{1}$, ismandianto@lecturer.unri.ac.id ${ }^{2}$
}

\begin{abstract}
ABSTRAK
Datariau.com merupakan salah satu media online erada di Pekanbaru yang berdiri sejak 20 Agustus 2012. Meskipun telah terverifikasi oleh Dewan Pers, masih terdapat ketidaksesuaian penulisan bahasa jurnalistik yang ditemukan di situs Datariau.com. Tujuan penelitian ini untuk mengetahui bagaimana penerapan bahasa jurnalistik di portal berita kategori Hukum Kriminal Datariau.com. Penelitian ini menggunakan teori pers tanggung jawab sosial. Pendekatan yang digunakan adalah kualitatif dengan metode deskriptif analisis. Informan dalam penelitian ini redaktur pelaksana, pimpinan redaksi dan wartawan Datariau.com. Sedangkan objek penelitiannya adalah berita kategori hukum kriminal dalam portal berita Datariau.com. Teknik pengumpulan data yang digunakan yakni observasi, wawancara, dan dokumentasi. Lokasi penelitian berada di kantor redaksi Datariau.com. Hasil penelitian menunjukkan bahwa penerapan bahasa jurnalistik di portal berita kategori hukum kriminal Datariau.com masih terdapat 65 ketidaksesuaian penulisan bahasa jurnalistik dan terdapat ketidaksesuaian 4 dari 5 ciri bahasa jurnalistik yaitu kata mubazir.
\end{abstract}

Kata-kata Kunci: Bahasa Jurnalistik, Jurnalistik, Datariau.com, Berita, Hukum Kriminal

\section{Application of Journalistic Language in the Category of Criminal Law Datariau.com}

\begin{abstract}
Datariau.com is one of the online media in Pekanbaru which was founded on August 20, 2012. Even though it has been verified by the Press Council, there are still discrepancies in the journalistic language found on the Datariau.com website. The purpose of this research is to find out how the application of journalistic language in the news portal in the Criminal Law category of Datariau.com. This research uses the theory of social responsibility press. The approach used is qualitative with descriptive analysis method. The informants in this study are managing editors, chief editors and journalists of Datariau.com. Meanwhile, the object of the research is criminal law news in the Datariau.com news portal. The data techniques used were observation, interviews, and documentation. The research location is in the editorial office of Datariau.com. The results showed that the application of journalistic language news portal in the criminal law category of Datariau.com still contained 65 journalistic language discrepancies and 4 out of 5 characteristics of journalistic language, namely redundant words.
\end{abstract}

Keywords: Language Journalism, Journalism, Datariau.com, News, Criminal Law 


\section{PENDAHULUAN}

Datariau.com merupakan salah satu media online di Pekanbaru, Riau, yang resmi berdiri pada 20 Agustus 2012 di bawah manajemen PT. Media Insan Nusantara Digital. Datariau memiliki tagline "Portal berita Sesuai Fakta" (Datariau.com, 2020). Sebagai media yang telah terverifikasi oleh dewan pers maka penulis ingin melihat bagaimana penerapan bahasa jurnalistik dalam poral berita kategori hukum kriminal di Datariau.com.

Gambar 1 Datariau.com terverifiksi Dewan Pers

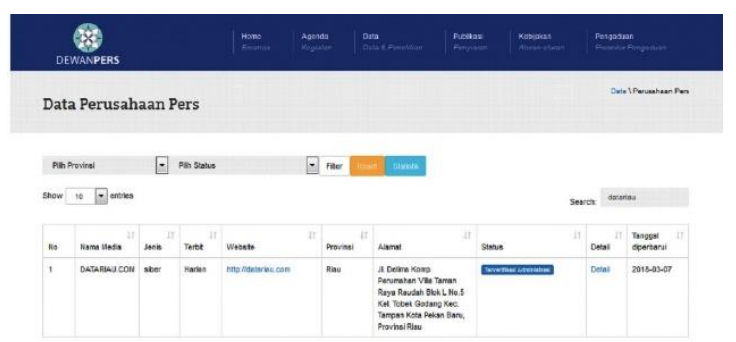

Sumber: Datariau.com, 2020.

Datariau.com memiliki banyak kategori berita. Di antaranya adalah kategori Sport, Politik, Nasional, Hukrim (Hukum Kriminal, Ekbis (Ekonomi Bisnis), Peristiwa, Pemerintahan, Internasional, Lingkungan, Sosial Budaya (SosBud), dan Kategori Tekno. Kategori berita hukum kriminal dalam Datariau.com selalu masuk ke dalam berita-berita terpopuler dan lebih banyak dibandingkan kategori lainnya. Hal inilah yang menjadi alasan penulis memilih kategori hukum kriminal.
Gambar 2 Berita Terpopuler Datariau.com 23 September 2020 TERPOPULER

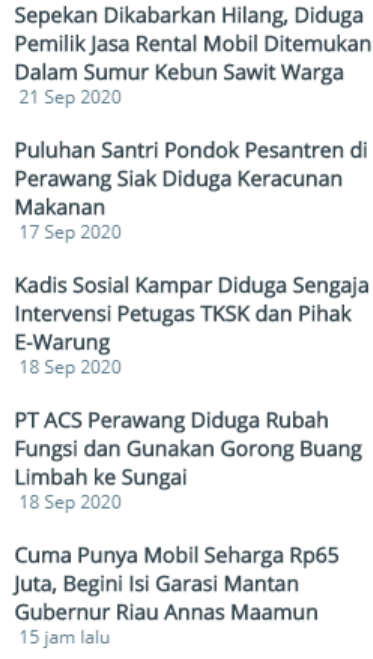

Sumber: Datariau.com, 2020

Berdasarkan hasil observasi yang penulis lakukan dalam berita yang terbit pada 19 September 2020 maka ditemukan beberapa kesalahan kesalahan bahasa jurnalistik di Datariau.com. Hal ini dapat dilihat dalam paragraf pertama berita berjudul Pengedar Sabu di Tapung Kampar Pura-pura Memancing Ikan Sambil menunggu pembeli yaitu "Unit Reskrim Polsek Tapung amankan 2 orang pengedar narkoba jenis sabu di areal perkebunan sawit milik warga di wilayah Desa Sari Galuh pada Jumat dinihari (18/9/2020)" (Datariau.com, 2020). Paragraf ini melanggar ciri bahasa jurnalistik yaitu tidak mubazir. Menurut penulis, kata "di wilayah" dihilangkan saja karena tidak mengubah makna dari kalimat tersebut.

Pada berita lain yang terbit pada 20 September 2020 yang berjudul Pengakuan 
Korban Pencabulan Oknum Polisi Pelanggar Lalu Lintas: Saya Diajak ke Kamar, Dikasih Air Putih dan Saya

Tertidur!. Dalam paragraf terakhir berita ini tertulis "Yang bersangkutan juga diduga melanggar aturan disiplin anggota polisi. Karena dia merupakan staf, bukan personel yang bertugas di lapangan," kata Kombes Pol Komaruddin” (Datariau.com, 2020). Diasumsikan oleh penulis melanggar ciri bahasa jurnalistik hemat kata. Seharusnya, untuk menutup pernyataan langsung di kalimat terakhir dalam sebuah berita, kata yang tepat adalah "pungkasnya".

Prof. Jhon Hohenberg menyatakan bahwa tujuan semua penelitian karya jurnalistik adalah menyampaikan informasi, opini, dan ide kepada pembaca secara umum. Informasi harus disampakan dengan teliti, ringkas, jelas, mudah dimengerti, dan menarik. Kata teliti berarti informasi yang disampakan harus benar, akurat dan tidak rekayasa berita. Kata ringkas dan jelas berarti kalimat-kalimat yang digunakan tidak bertele-tele, kata-kata yang digunakan tepat secara semantik dan gramatikal. Kata mudah dimengerti berarti para pembaca tidak perlu buang energi (untuk membuka kamus) mencari makna kata atau kalimat yang digunakan. Sedangkan kata menarik berarti berita yang disampaikan disusun dalam kalimatkalimat atau kata-kata yang menarik sehingga orang lain tertarik membacanya (Chaer, 2010:2).

Bahasa jurnalistik atau bahasa pers, merupakan salah satu ragam bahasa kreatif bahasa Indonesia, di samping terdapat juga ragam bahasa akademik (ilmiah), ragam bahasa usaha (bisnis), ragam bahasa filosofik, dan ragam bahasa literer (sastra) (Suroso, 2010:1). Sudirman Sudirman (2005:118) mengatakan "Dunia pers juga memiliki kaidah-kaidah bahasa agar bahasa yang digunakan dalam menyampaikan informasi lebih mudah lagi dipahami dan tidak membosankan khalayak. Prinsipnya bahasa jurnalistik itu harus jelas, padat, ringkas, dan lugas".

Pemimpin redaksi majalah kebudayaan Basis (Yogyakarta), Dick Hartono, pernah mengatakan bahwa dalam bahasa itu terungkap sistem nilai dan lambang yang dianut dan dipakai oleh bangsa yang bersangkutan. Dalam bahasa tulis kita mengenal apa yang disebut dengan langgam bahasa jurnalistik, langgam bahasa sastra, bahasa ilmiah, bahasa sandi, dan sebagainya. Jenis bahasa jurnalistik berbeda dengan bahasa tulisan umumnya. Bahasa Tulis tersebut tidak boleh melanggar kaidah berbahasa atau tata bahasa baku (Barus, 2011:2013). Bahasa jurnalistik adalah gaya bahasa yang digunakan wartawan dalam menulis berita. Disebut sebagai bahasa komunikasi massa (language of mass communication atau 
newspaper language), yakni bahasa yang digunakan dalam komunikasi melalui media massa, baik komunikasi lisan (tutur) di media elektronik (Radio dan TV) maupun komunikasi tertulis (media cetak), dengan ciri khas singkat, padat dan mudah dipahami.

Kunjana Rahardi dalam bukunya Asyik Berbahasa Jurnalistik memberikan ringkasan untuk sosok bahasa dalam ragam bahasa jurnalistik atau bahasa pers memiliki ciri komunikatif, spesifikasi, hemat kata, jelas makna, tidak mubazir dan klise (Rahardi, 2006). Sosok bahasa di dalam ragam jurnalistik atau bahasa per situ sesungguhnya menunjuk pada bahasa yang dipakai untuk menyampaikan sosok fakta, laporan, berita, tulisan, yang terjadi kini, yakni fakta yang memang terjadi hari ini, bahkan pada saat sekarang ini.

Dalam penelitian ini, penulis menggunakan teori pers tanggung jawab sosial. Sistem pers tanggung jawab sosial merupakan suatu teori yang mempunyai asumsi utama bahwa kebebasan memiliki nilai yang sepadan dengan tanggung jawab atas kebebasan tersebut. Kebebasan dalam sistem ini bukanlah suatu kebebasan yang mutlak atau absolut. Penulis bahasa jurnalistik memiliki standar yang digunakan sehingga menjadi hal yang perlu dipertanggungjawabkan oleh media online Datariau.com kepada masyarakat.
Penelitian ini didukung oleh beberapa penelitian terdahulu. Salah satunya adalah penelitian yang dilakukan oleh Henatisya, Achmad Herman, dan Andi Akifah tahun 2016 Universitas Tadulako dengan judul "Penerapan Bahasa Jurnalistik dalam Penelitian Nama Siar Sulteng Fakual di LPP TVRI Sulteng" memiliki perbedaan dalam menggunakan teori. Teori yang digunakan oleh Henatisya dkk adalah teori skema sedangkan penelitian yang penulis lakukan menggunakan teori tanggung jawab sosial. Penelitian sebelumnya meneliti masalah ketepatan, kepadatan, kejelasan, kesederhanaan, kepercayaan sedangkan penelitian ini meneliti masalah komunikatif, spesifikasi, hemat kata, jelas makna, tidak mubazir dan klise.

Penelitian berikutnya dilakukan oleh Septyana Yundari pada tahun 2018 Universitas Riau dengan judul "Implementasi Bahasa Jurnalistik pada Pemberitaan Hukum Kriminal Portal Berita www.goriau.com" memiliki perbedaan dalam masalah yang diteliti. Penelitian yang dilakukan oleh Septyana Yundari meneliti masalah pemilihan kata, gramatikal, lugas, dan penggunakan kalimat aktif sedangkan penelitian yang penulis lakukan meneliti masalah komunikatif, spesifikasi, hemat kata, jelas makna, tidak mubazir dan klise.

Dalam penelitian ini, penulis menggunakan teori pers tanggung jawab 
sosial. Sistem pers tanggung jawab sosial merupakan suatu teori yang mempunyai asumsi utama bahwa kebebasan memiliki nilai yang sepadan dengan tanggung jawab atas kebebasan tersebut. Kebebasan dalam sistem ini bukanlah suatu kebebasan yang mutlak atau absolut.

Berita Kategori Hukum Kriminal pada portal berita Datariau.com, penulis mengambil 10 berita. Penelitian dilaksanakan pada bulan September 2020. Penelitian bertujuan untuk menganalisis bagaimana penerapan bahasa jurnalistik dalam portal berita Datariau.com. Dan untuk mengetahui apa saja ketidaksesuaian ciri bahasa jurnalistik pada kategori berita hukum kriminal

\section{METODOLOGI}

Pendekatan yang digunakan dalam penelitian ini adalah kulitatif dengan metode deskriptif analisis. Subjek dalam penelitian ini Redaktur Pelaksana, Pimpinan Redaksi dan Wartawan Datariau.com. Objek penelitian adalah berita kategori hukum kriminal dalam portal berita Datariau.com. Teknik pengumpulan data yang digunakan yakni observasi, wawancara, dan dokumentasi. Lokasi penelitian berada di kantor redaksi Datariau.com. Moleong (2010:132) mendeskripsikan subjek penelitian sebagai informan. Informan dalam penelitian ini adalah wakil pimpinan redaksi

Datariau.com, Redaktur Pelaksana

Datariau.com, dan Wartawan

Datariau.com

Dalam penelitian ini penulis menggunakan triangulasi metode. Triangulasi metode dilakukan agar formasi atau data yang berasal dari hasil wawancara dan analisis penerapan bahasa jurnalistik pada portal berita hukum kriminal Datariau.com diuji dengan hasil observasi dan seterusnya.

\section{HASIL DAN PEMBAHASAN}

Penerapan Bahasa Jurnalistik

\section{Datariau.com}

Bahasa jurnalistik didefinisikan sebagai bahasa yang digunakan oleh wartawan, redaktur, atau pengelola media massa dalam menyusun dan menyajikan, memuat, menyiarkan, dan menayangkan berita serta laporan peristiwa atau pernyataan yang benar, aktual, penting dan atau menarik dengan tujuan agar mudah dipahami isinya dan cepat ditangkap maknanya (Sumadiria, 2010:7).

Wartawan Datariau.com tidak semua berlatar belakang pendidikan di bidang jurnalistik. Seperti yang disampaikan oleh Wakil Pimpinan Redaksi Datariau, Mirdas Aditya.

"Tidak, karena ada pelatihan khusus
jurnalistik untuk pembekalan wartawan
baru yang memiliki latar belakang
pendidikan bukan dari jurusan ilmu
jurnalistik"(Hasil wawancara dengan
Mirdas Aditya 28 Januari 2021)


Berdasarkan hasil wawancara terkait penerapan bahasa jurnalistik, Redaktur Pelaksana Datariau.com melakukan pemeriksaan ulang minimal 3 kali sebelum diterbitkan termasuk menelaah bahasa Jurnalistik dalam pemberitaan.

"Seharusnya memang setiap wartawan memahami Bahasa Jurnalistik. Kita selalu sampaikan dalam rapat proyeksi dan pelatihan tahunan kepada para tim redaksi" (Hasil wawancara dengan Samsul Bahri, 28 Januari 2021)

Bahasa Jurnalistik, menurut Denni France (wartawan Datariau.com) adalah komunikasi massa yang digunakan dalam penelitian berita untuk menyampaikan informasi kepada publik. Dalam penyuntingan sebuah berita, seorang redaktur menjadikan bahasa jurnalistik sebagai indikator agar bahasa, ejaan, dan keefektifan kalimat dapat terpenuhi.

\section{Ketidaksesuaian Bahasa Jurnalistik}

\section{Datariau.com}

Bahasa pers itu haruslah memerhatikan dan memahami kelima ciri bahasa dalam ragam jurnalistik. komunikatif, spesifikasi, hemat kata, jelas, tidak mubazir dan tidak klise (Rahardi, 2017)

Ketidaksesuaian komunikatif seperti kalimat yang ditulis tidak langsung kepada pokok masalah masih ditemukan dalam 10 berita yang telah dianalisis. Begitu juga dengan ciri bahasa jurnalistik spesifik di mana dalam berita masih terdapat bentuk kebehasaan yang tidak sederhana. Selain itu, penggunaan kata yang tidak ekonomi yaitu bentuk bahasa yang digunakan dalam bahasa jurnalistik memiliki sedikit karakter kata atau huruf, dan terdapat ketidaksesuaian kata.

\section{Gambar. 3. Berita hukum dan kriminal}

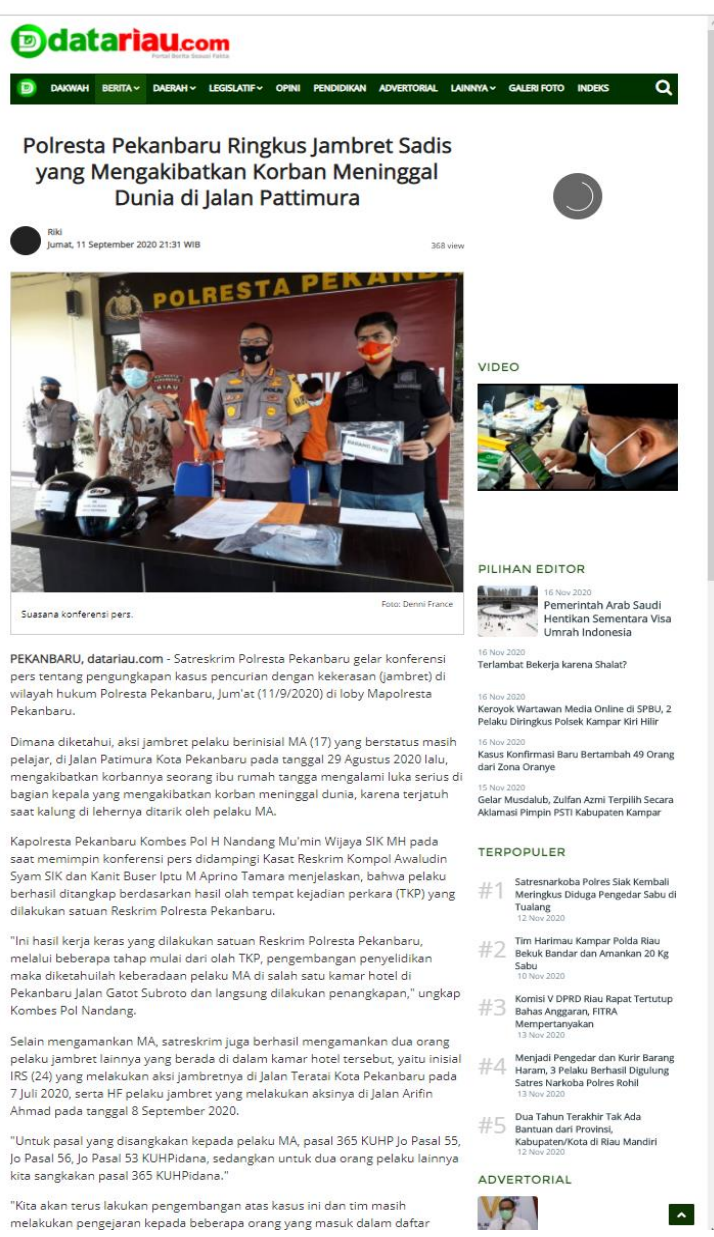

Sumber: Datariau.com

Berita berjudul "Polresta Pekanbaru Ringkus Jambret Sadis yang Mengakibatkan Korban Meninggal Dunia di Jalan Pattimura" melanggar 2 dari 5 ciri bahasa jurnalistik. Ciri bahasa 
jurnalistik paling sering mengalami kesalahan adalah komunikatif.

Dalam berita ini, terdapat 3 kesalahan ciri bahasa jurnalistik komunikatif di paragraf 1, 2, dan 6. Kesalahan komunikatif dalam berita ini karena kalimat yang ditulis masih berbelit-belit dan tidak langsung pada pokok permasalahan. Berita ini juga melanggar ciri bahasa jurnalistik tidak mubazir yaitu sebanyak 2 kali dalam paragraf 2 dan 6 karena masih menggunakan kata yang jika dihilangkan tidak mengubah makna kalimat dalam berita. Namun dalam berita ini penerapan bahasa jurnalistik spesifik, hemat kata dan jelas makna sudah diterapkan dengan baik. Hal ini dapat dibuktikan dengan tidak adanya kesalahan dalam berita yang telah dianalisis.

Penerapan bahasa jurnalistik sudah dilakukan dalam penulisan berita hukum kriminal Datariau.com Namun, dalam penerapan ciri bahasa jurnalistik tidak mubazir, Datariau.com masih ditemukan 27 ketidaksesuaian dalam penulisannya.

Analisis dengan menggunakan teori tanggung jawab sosial, terlihat bahwa Datariau.com sudah berupaya memenuhi kewajiban sebagai media yang mengabdi terhadap kepentingan masyarakat dengan mencoba menulis berita yang baik sesuai dengan kode etik serta bahasa jurnalistik. Teori ini memandang perlu adanya pers dan sistem jurnalistik yang menggunakan dasar moral dan etika (Rati, 2016:20). Namun berdasarkan hasil analisis, Datariau.com belum sepenuhnya memenuhi tanggung jawab media untuk menulis berita dengan baik yang sesuai dengan bahasa jurnalistik.

Hasil dari wawancara menjelaskan bahwa Datariau.com berpedoman pada bahasa jurnalistik dan sesuai dengan EYD. Redaktur Pelaksana Datariau.com menjelaskan bahwa telah melakukan pemeriksaan ulang minimal 3 kali sebelum diterbitkan serta menjadikan bahasa jurnalistik sebagai indikator penyuntingan berita yang diterbitkan.

Namun dalam analisis yang penulis lakukan, penulis menemukan 65 kesalahan bahasa jurnalistik dari 88 paragraf yang terdiri dari 106 kalimat. untuk lebih jelas penulis sajikan dalam bentuk tabel berikut ini:

Tabel 1. Ketidaksesuaian Bahasa Jurnalistik Datariau.com No Ciri-ciri Bahasa Frekuensi Jurnalistik

\begin{tabular}{clc}
\hline $\mathbf{1}$ & Komunikatif & 18 \\
\hline $\mathbf{2}$ & Spesifik & 13 \\
\hline $\mathbf{3}$ & Hemat kata & 7 \\
\hline $\mathbf{4}$ & Jelas makna & - \\
\hline $\mathbf{5}$ & Tidak Mubazir dan & 27 \\
& tidak klise & \\
&
\end{tabular}

Sumber: Penelitian penulis , 2020

Berdasarkan tabel di atas, dapat dilihat bahwa ciri bahasa jurnalistik yang paling sering dilanggar adalah mubazir dan klise. Maka ketidaksesuaian bahasa jurnalistik 
dalam berita hukum kriminal Datariau.com adalah komunikatif, spesifik, hemat kata, tidak mubazir dan tidak klise. Selain itu, dalam penelitian ini, penulis memukan kesalahan lain seperti kesalahan ketik, penulisan kata yang tidak baku, penulisan paragraf yang hanya terdiri dari 1 kalimat, serta kesalahan penulisan preposisi.

Berdasarkan 10 berita yang telah dianalisis, penulis menemukan bahwa ciri bahasa jurnalistik komunikatif masih banyak terdapat ketidaksesuaian penulisan. Dari 106 kalimat terdapat 18 ketidaksesuaian ciri bahasa jurnalistik komunikatif. Berita kategori hukum kriminal masih ditemukan kalimat yang berbelit-belit sehingga penyampaian informasi menjadi tidak komunikatif.

Selanjutnya penerapan ciri bahasa jurnalistik spesifik terdapat 13 ketidaksesuaian dari 106 kalimat yang dianalisis. Penulisan kalimat yang terlalu panjang sehingga bahasanya menjadi tidak sederhana. Selain itu, penerapan ciri bahasa jurnalistik hemat kata ditemukan 7 ketidaksesuaian penulisan. Hal ini dikarenakan Datariau.com menggunakan kata yang tidak minim karakter. Namun, penerapan ciri bahasa jurnalistik spesifik merupakan ciri yang sedikit dilanggar.

Penerapan ciri bahasa jurnalistik jelas makna dalam berita kategori hukum kriminal di portal berita Datariau.com sudah diterapkan dengan baik. Hal ini dibuktikan dari analisis yang telah penulis lakukan pada 10 berita hukum kriminal, tidak ditemukan ketidaksesuaian ciri bahasa jurnalistik jelas makna. Namun, dalam penerapan ciri bahasa jurnalistik mubazir, ditemukan 27 ketidaksesuaian penulisan. Sehingga, penerapan bahasa jurnalistik yang belum diterapkan dengan baik.

Teori pers tanggungjawab sosial adalah tanggung jawab media atau pers yang berupaya menunjukan pada suatu konsep tentang kewajiban media untuk mengabdi terhadap kepentingan masyarakat (Rati, 2016:19). Sehingga hubungan teori dengan penelitian ini merujuk kepada hasil wawancara penulis menyimpulkan bahwa Datariau.com sudah berupaya memenuhi kewajiban sebagai media yang mengabdi terhadap kepentingan masyarakat dengan mencoba menulis berita yang baik sesuai dengan kode etik serta bahasa jurnalistik. Namun berdasarkan hasil analisis, Datariau.com belum sepenuhnya memenuhi tanggung jawab media untuk menulis berita dengan baik yang sesuai dengan bahasa jurnalistik.

\section{KESIMPULAN}

Berdasarkan penelitian yang telah dilakukan oleh penulis, maka dapat disimpulkan bahwa Datariau.com dalam menulis berita kategori hukum kriminal masih terdapat ketidaksesuaian 4 dari 5 ciri 
bahasa jurnalistik. Adapun bahasa jurnalistik yang masih terdapat ketidaksesuaian adalah komunikatif, spesifik, hemat kata, jelas makna dan tidak mubazir. Penulis melakukan analisis terhadap 106 kalimat dan ditemukan 65 ketidaksesuaian.

Aaran yang penulis ingin sampaikan yaitu: (1) Redaksi atau wartawan portal berita Datariau sebaiknya perlu memperhatikan lagi penulisan beritanya agar tidak terdapat kesalahan-kesalahan seperti kata mubazir, komunikatif, spesifik, hemat kata, serta memperhatikan penulisan paragraf agar paragraph dalam berita Datariau tidak lagi hanya terdiri dari 1 kalimat. (2) Untuk Mahasiswa jurnalistik, penulis mengharapkan agar lebih mempelajari dan menguasai bahasa jurnalistik terutama bagi yang berimnat bekerja di sebuah media agar tercipta jurnalis yang kompeten.

\section{DAFTAR PUSTAKA}

Barus, S. W. (2011). Jurnalistik. Jakarta: Erlangga.

Chaer, A. (2010). Bahasa Jurnalistik. Jakarta: Rineka Cipta.

Datariau.com. (2020, $20 \quad$ September). Pengakuan Korban Pencabulan Oknum Polisi Pelanggar Lalu Lintas: Saya Diajak Ke Kamar Dikasih Air Putih dan saya tertidur. Diakses pada Agustus 2020, dari http://www.Datariau.com/detail/berita/pengakuan-korban-pencabulan-oknumpolisi-pelanggar-lalu-lintas--saya-diajakke-kamar--dikasih-air-putih-dan-sayatertidur--
Datariau.com. (September 2020). Susunan Redaksi. Diakses Pada Desember 2020, Dari https://www.Datariau.com/statis/susunan -redaksi

Moleong, L. . (2010). Metodologi Penulisan Kualitatif. Bandung: Remaja Rosda Karya.

Rahardi, K. (2006). Berbahasa Jurnalistik. Yogyakarta: Santusta.

Rati, A. (2016). Etika Wartawan Dalam Peliputan Berita Kriminal Di Inewstv Sumsel. 53(9), 1-21.

Sudirman, T. (2005). Jurnalistik Baru. Jakarta: Kalam Indonesia.

Sumadiria, H. (2010). Bahasa Jurnalistik Panduan: Praktis Penulis dan Jurnalis. Bandung: PT Remaja Rosdakarya.

Suroso. (2010). Menuju Pers Demokratis: Kritik atas Profesionalisme Wartawan. Yogyakarta: LSIP. 